\title{
CO CREAR CON EL DIGITAL EN UN MUNDO EN MUTACIÓN
}

\author{
AUTORES: MORENO, Carlos \\ Catedrático - Asesor Científico, Experto Internacional en Ciudades Inteligentes - Paris, Francia \\ carlos.moreno@inti-mc.com
}

\section{Resumen}

\begin{abstract}
A través de los tiempos, la acción del hombre ha adoptado diferentes formas. El auge de la tecnología digital en el siglo XXI permite desplegar de una forma muy interesante la dimensión colaborativa de la acción. Porque, a través de todo lo que el poder de la tecnología digital permite compartir, se potencia y se amplifica el efecto de transformación. Así, con la tecnología digital, creamos nuevas formas de trabajar basadas en el intercambio y la colaboración. Y la instauración de estos nuevos comportamientos virtuosos transforma a su vez al mundo. Al colaborar, ponemos herramientas y conocimientos en común. Al compartir, creamos nuevos servicios y nuevos usos. El open source, el opendata, el crowdsourcing y el crowdfunding son otras tantas formas modernas del actuar
\end{abstract}

colaborativo. En un mundo urbanizado, estas tecnologías impactan nuestra percepción de mundo real. Es la hora de movilizarnos a través de la hyper proximidad, de la cual considero que la toma de conciencia de su importancia es indispensable para crear una verdadera conciencia ciudadana digital enraizada en la vida real y cotidiana para desarrollar su poder transformador".

\section{Palabras Clave}

Empoderamiento, Ciudad compartida ,Creación, Colaboración, Multitud, Mutación urbana.

\section{1. "Crear y actuar con el digital en un mundo en mutación"}

« Vamos hacia un mundo donde el humano tendrá el poder de un verdadero dios, pero habría que comenzar a aprender hacer este trabajo!» Con estas palabras el artista Jaron Lanier [1] marca la paradoja a donde nos conduce la evolución exponencial del progreso tecnológico. La revolución digital ofrece oportunidades inéditas de creatividad, de diálogo y de emancipación. Pero al mismo tiempo que nos pesan en nuestra vida cotidiana las amenazas ecológicas, económicas, sociales o climáticas que necesitan soluciones a la escala global, ella recompone nuestras realidades y replantea todos nuestros posicionamientos tradicionales.

¿Frente a estos desafíos a la complejidad del mundo y a la necesidad imperiosa de imaginar, crear y actuar en un mundo en permanente transformación cómo proyectarse hacia la construcción de nuevas historias colectivas? Como abordar la convergencia entre el poderío del digital y la necesidad de actuar en nuestro mundo real y cotidiano?

En la actualidad, la omnipresencia de la ubicuidad, la fuerza de las redes sociales, del internet de los objetos y la hyper connnectividad, pero también la emergencia de un mundo altamente urbanizado, plantea nuevos paradigmas culturales que se desarrollan a la escala de las ciudades con otras percepciones del espacio y la temporalidad. Estas transforman el ser urbano en profundidad haciendo emerger nuevas formas de comportamiento atravesadas por el digital con nuevos modelos y dentro de ellos los colaborativos surgidos en esta dinámica de transformación. 
Mas allá de estos nuevos modelos culturales, nuestra interrogación va hacia como considerar la acción individual y colectiva en este nuevo contexto cuando se construyen otras manera de crear, producir y ante todo de relacionarse con los otros. Un resurgimiento de la practica de la Alteridad [2] toma forma en este nuevo paradigma si deseamos que el acto creativo sea asociado con el placer del compartirlo y generar un sentido de servicio hacia los otros. Transformar un comportamiento individual creativo en una acción concreta colectiva de servicio contribuye así a hacer emerger nuevos modelos sociales. Pero esto significa cuestionarse sobre la noción misma de la acción.

Reflexionar sobre el alcance y el sentido de la acción en el siglo XXI, cuando la tecnología digital se ha convertido en una importante herramienta de transformación, supone revisar primero el significado de la palabra "acción”. La acción encierra la idea de movimiento del que va a resultar una transformación de lo real; pero sobre todo la acción entraña la idea del potencial que libera esta transformación. La acción abre posibilidades y en esto no hay que con- fundir actuar y hacer. Como subrayaba Aristóteles, existe un poder, una dinámica y una potencialidad en cada acción, de las que surge una transformación de la realidad más allá del simple ámbito de la acción inicial [3].

Por otra parte, el mundo del siglo XXI está marcado por la tecnología digital, a la vez ciencia, herramienta y poderoso instrumento de mutación que encierra un considerable potencial de transformación del mundo y representa un medio de acción inédito para los seres humanos.

No hay que olvidar que para actuar es indispensable comprender bien el mundo en el que se va a inscribir esa acción. "Cuando el sabio señala la luna, el necio mira el dedo", decía Confucio. No miremos únicamente el dedo de la digitalidad y recordemos que lo que nos interesa es el mundo, es decir, todo lo que constituye nuestra vida cotidiana. La tecnología digital tiene que ayudarnos a comprender el mundo para transformarlo, no constituye un fin en sí mismo para el hombre.

\section{Actuar, colaborar y compartir}

A través de los tiempos, la acción del hombre ha adoptado diferentes formas. El auge de la tecnología digital en el siglo XXI permite desplegar de una forma muy interesante la dimensión colaborativa de la acción. Porque, a través de todo lo que el poder de la tecnología digital permite compartir, se potencia y se amplifica el efecto de transformación. Así, con la tecnología digital, creamos nuevas formas de trabajar basadas en el intercambio y la colaboración. Y la instauración de estos nuevos comportamientos virtuosos transforma a su vez al mundo. Al colaborar, ponemos herramientas y conocimientos en común. Al compartir, creamos nuevos servicios y nuevos usos. El open source, el opendata, el crowdsourcing y el crowdfunding son otras tantas formas modernas del actuar colaborativo.

Ahora, la acción ya no es asunto de especialistas que dominan el saber y las tecnologías. Gracias a la cola- boración y al intercambio, vemos aparecer nuevas aplicaciones que repercuten en nuestras vidas. A partir de ahora, con el open source, se pueden crear aplicaciones que antes requerían la intervención de especialistas. Los "hackhatons" nos enseñan cómo los jóvenes pueden crear soluciones operativas inéditas en un fin de semana. Hemos entrado en la era de la "appstitud", esto es, una actitud que consiste en compartir y colaborar, y resulta posible gracias al poder de lo digital.

Así, con la digitalidad, nuevas maneras de formalizar el cambio han podido hacerse realidad. Antes, se actuaba de forma aislada, se seguía a un jefe, se obedecía a los superiores jerárquicos, se observaba una estrategia de cambio. Ahora se puede ser protagonista del cambio, se puede suscitar la sorpresa, se puede dar origen a una auténtica creación apoyándose en la inmensidad de recursos que la tecnología digital pone a disposición de cada uno. 


\section{Actuar, yo y los demás}

Así las cosas, me parece esencial incluir la noción de alteridad para llegar más lejos. Pienso que, en el siglo XXI, solo tiene sentido actuar inscribiéndose en una inteligencia colectiva si uno es capaz de aportarle una visión propia, apta al propio tiempo para comprender la visión del otro. Como, ahora, cada uno puede programar y acceder al open source, la noción de acción no significa únicamente poner conocimientos tecnológicos en común. De un modo más profundo significa también transformar su mirada hacia el otro.

La auténtica construcción de un futuro más sereno dependerá, creo yo, de nuestra capacidad para cambiar también nuestra mirada hacia el otro. La digita- lidad también debe permitirnos salir de una lógica de oposición y poder para acceder a una lógica de comprensión de las aportaciones y las diferencias. Ya nos está enseñando hasta qué punto estas diferencias son una fuente de creatividad.

Llegados a este punto, me gustaría introducir la noción de empatía [4], que considero un componente esencial del proceso de co-creación del mundo del mañana. Al sentir la emoción que experimenta el otro, la respeto y le doy una perspectiva. La empatía es crucial para actuar, cambiar, co-crear, coescribir según un modo disruptivo. Porque la disrupción supone ver las cosas desde otro punto de vista diferente del mío.

\section{Actuar, la multitud y la tecnología digital}

Gracias a la digitalidad, se crean nuevas relaciones entre el yo, el otro y la multitud. Con la ayuda de estas nuevas herramientas, hoy en día tenemos la suerte de poder desarrollar un sistema empático para compartir, colaborar y transformar el mundo, sin necesidad de proximidad física con los demás. Con esta "hyper proximidad" [5] se puede actuar con la multitud, sin que cada cual deje de ser diferente. Hay que subrayar la fuerza de la multitud a la hora del Internet de las cosas; todos tenemos la capacidad de aportar algo diferente, que nos es propio. La acción se inscribe en un mallado multiplicador, en el que cambia la visión que tenemos los unos de los otros. Al poner en común situaciones de la vida, y aportar cada uno sus propias soluciones, estamos coescribiendo cosas nuevas.

La tecnología digital puentea todos los espacios y todos los tiempos, revelándose como una herramienta extraordinaria. Al inscribirse en un espacio socio-territorial dado, nos ofrece una auténtica capacidad de reinventar nuestras vidas. '

Tal es el reto que deberemos levantar en el siglo XXI: devolver a la alteridad y también al altruismo, - como parte integrante de la cultura del respeto de la mirada del otro-, todo el lugar central que deberían tener, apoyándonos en la fuerza transformadora como herramienta de la revolución tecnológica. Como lo ha expresado Milad Doueihi [6], se trata de reivindicar así un " humanismo digital ", convencidos que el digital, puede ser llevado en una perspectiva de creación de nuevas formas de humanidades y urbanidades. Tenemos un espacio posible ante nosotros de creatividad para que las tecnologías conectadas, nos ayuden a anclar la empatía y el altruismo en un espacio social y territorio dados. Con la capacidad de conectarse sin interrupción, asistimos al desarrollo de esta hyperproximidad entre los ciudadanos, que nos muestra que las nuevas sociedades de compartir y de colaboración podrían ser posibles. Dejamos entonces el mundo de la utopía tecno céntrica y neo positivista, para que el imaginario y su hibridación en la realidad, le de paso en la acción a la alteridad y la empatía, aquí y ahora. 


\section{Referencias}

- Lanier Jaron (2014). Who Owns the Future? Paperback, March.

- Emmanuel Lévinas (2006). Altérité et transcendance, LGF.

- Timothy O'Connor \& Constantine Sandis (eds.) (2010). A Companion to the Philosophy of Action, Wiley-Blackwell, Oxford.
- Frans de Waal (2010). L'Âge de l'empathie; Leçons de la nature pour une société solidaire; Éd. Les Liens qui Libèrent.

- Carlos Moreno (2015). Le Monde à 50 ans, l'intelligence humaine et ses défis Revue Prospective Stratégique, Paris (En español aquí).

- Milad Doueihi, «Pour un humanisme numérique », Seuil, 2011, Paris.

\section{Forma de Citación}

MORENO, Carlos: Co crear con el digital en un mundo en mutación. Revista Communication Papers, $\mathrm{N}^{\circ} 8$ (Monográfico II), páginas 50 a 53. Departamento de Filología y Comunicación de la Universidad de Girona. Recuperado el __ de de 2 de: http://www.communicationpapers.es 